\title{
The epidemiology of pituitary adenomas in Iceland, 1955-2012: a nationwide population-based study
}

\author{
Tomas Thor Agustsson 1,2, Tinna Baldvinsdottir ${ }^{1,2}$, Jon G Jonasson ${ }^{2,3,4,5}$, \\ Elinborg Olafsdottir ${ }^{5}$, Valgerdur Steinthorsdottir ${ }^{2,6}$, Gunnar Sigurdsson ${ }^{1,2}$, \\ Arni V Thorsson ${ }^{1,2,6}$, Paul V Carroll7, Márta Korbonits ${ }^{8}$ and Rafn Benediktsson ${ }^{1,2}$ \\ ${ }^{1}$ The Department of Endocrinology and Metabolic Medicine, Landspítali - The National University Hospital of \\ Iceland. Fossvogur, 108 Reykjavík, Iceland, ${ }^{2}$ The Faculty of Medicine, The University of Iceland, Vatnsmýrarvegur 16, \\ 101 Reykjavík, Iceland, ${ }^{3}$ The Department of Pathology, Landspítali - The National University Hospital of Iceland, \\ Fossvogur, 108 Reykjavík, Iceland, ${ }^{4}$ The Icelandic Cancer Registry, Skógarhlíð 8, 105 Reykjavík, Iceland, \\ ${ }^{5}$ deCODE genetics, Sturlugata 8, 101 Reykjavík, Iceland, ${ }^{6}$ The Paediatric Department, Landspitali - The National \\ University Hospital of Iceland, Hringbraut, 101 Reykjavík, Iceland, ${ }^{7}$ The Department of Diabetes and Endocrinology, \\ Guy's and St Thomas' NHS Foundation Trust, Westminster Bridge Road, London, SE1 7EH, UK and \\ ${ }^{8}$ Endocrinology, The William Harvey Research Institute, Barts and The London School of Medicine, \\ Queen Mary University of London, London EC1M 6BQ, UK
}

\author{
Correspondence \\ should be addressed \\ to T T Agustsson \\ Email \\ tomasa@landspitali.is
}

\begin{abstract}
Objective: Pituitary adenomas (PA) are among the most common human neoplasms. To describe the epidemiology and assess the disease burden of clinically significant PAs, population-based studies are needed. Iceland has a small well-defined population. The aim of this study is to describe the epidemiology of PAs in Iceland over an expanded period of time. Design: This is a retrospective observational study, including all PAs diagnosed in Iceland from 1955 to 2012. Methods: Extensive clinical information was gathered in a database. Prevalence rates for all PA subtypes were calculated along with standardized incidence rates (SIR). Sex ratios and relationships with adenoma size, age, and symptoms were assessed.

Results: We identified 471 individuals: 190 men and 281 women. Total prevalence in 2012 was 115.57/100 000, prolactinomas were most prevalent $(54.37 / 100000)$ followed by non-functioning adenomas (NFPAs) $(42.32 / 100000)$. Throughout the period, NFPAs were most common (43.0\%) followed by prolactinomas (39.9\%) and $11.3 \%$ had acromegaly and $5.7 \%$ Cushing's disease. Women are diagnosed younger with smaller adenomas. Total SIR has increased significantly and is now 5.8/100 000 per year.

Conclusion: In this nationwide study spanning six decades, we have confirmed PAs rising prevalence and incidence rates noted in recent studies. We demonstrated higher overall prevalence and incidence rates than ever previously recorded with an increasing predominance of NFPAs, which is not explained by incidental findings alone. There is a relationship with the introduction of imaging modalities, but the vast majority of patients are symptomatic at diagnosis. This underlines the importance of increased awareness, education, and appropriate allocation of resources for this growing group of patients.
\end{abstract}

\section{Introduction}

Pituitary adenomas (PAs) are usually indolent and benign. They can be associated with hormonal hypersecretion, local mass effect, hypopituitarism, and adverse results of therapy causing significant morbidity $(1,2,3,4,5)$. A proportion is still asymptomatic and remains undetected.
(C) 2015 European Society of Endocrinology Printed in Great Britain
Published by Bioscientifica Ltd. 
The interpretation of earlier epidemiology data on PAs is challenging, and it is only within the last decade that more intensive population-based studies have begun to emerge enabling assessment of their true disease burden and associated costs. Some studies report prevalence data $(6,7,8,9)$ and a few report incidence rates $(8,10)$. These studies indicate a rise in both prevalence and incidence. It may remain uncertain whether some of the results of these studies are related to specific populations, genetics, areas, or time periods. The addition of this comprehensive longitudinal analysis based on a homogenous population may help confirm and clarify some of these points.

Iceland has a small, well-defined population with access to extensive clinical data over an extended period of time. This provides a unique opportunity for in-depth epidemiological studies. The aim of this study is therefore to define the prevalence and incidence rates of all types of PAs in Iceland over the last 58 years, explore possible contributing factors to rate variations, and compare with other recent population-based epidemiological data.

\section{Subjects and methods}

\section{Study population}

Iceland is an island in the middle of the North Atlantic Ocean with a growing population of $\sim 330000$ people with a limited immigration for the last few centuries. Icelanders have kept a unique and accurate set of genealogical records since the time of first settlement in the late ninth century (11). Iceland has a national health service, and patients requiring investigations or treatment for suspected pituitary disease will be seen at a limited number of facilities from which there is relatively easy access to extensive clinical information. All patients diagnosed with a PA at any site in Iceland during the period of 1955-2012 were included in the study. Considering the defined nature of the extensive data available, the whole Icelandic population provides a suitable background for the purpose of this analysis. Information about the exact population size at different times (Table 1) was obtained from Statistics Iceland (Hagstofa Islands).
The study was approved by the Icelandic Data Protection Authority and Icelandic National Bioethics Committee.

\section{Data gathering}

A database recording all instances of PAs in the total population of Iceland during 1955-2012 was constructed. Information was obtained from medical records at the National University Hospital of Iceland and the three district general hospitals in Iceland, from the records of all privately practicing endocrinologists and gynaecologists in the country, the Icelandic Cancer Registry, the department of pathology, all four radiology departments in the country, and the Icelandic Heart Association (IHA). IHA has conducted studies focusing on multiple causes of disability, including cerebrovascular disease and Alzheimer's, which include cranial imaging where a few PAs were initially diagnosed. Initial search criteria were broad to include a range of endocrinological- and CNS-related diagnoses to minimise a change of missed cases (ICD-10: D33, D35, D43, D44, E22, E23, E24, E29, E31, E34, E35). Each case was reviewed and the diagnosis of a PA was confirmed by a consultant endocrinologist where appropriate. All diagnoses were verified by at least two consultant endocrinologist through scrutinizing clinical, hormonal, pathological, and imaging data. The data recorded included diagnosis, gender, age at diagnosis, presenting symptoms, adenoma size, findings on imaging, biochemical findings prior to and following treatment, details of medical and surgical treatments, histopathological findings (including immunohistopathological staining, invasiveness, and markers of proliferation and atypia), and details of follow-up. The database is incorporated into the patient record system at the National University Hospital of Iceland.

Adenoma subtypes were classified according to hormonal secretion. All adenomas with no evidence of hormonal hypersecretion were defined as non-functioning pituitary adenomas (NFPAs). Prolactinomas were defined as adenomas associated with hyperprolactinaemia (above local reference ranges defined by sex), whereas all other causes had been considered and eliminated, including stalk compression. Patients with hyperprolactinaemia and

Table 1 Changes in total prevalence rates and age SIR of pituitary tumours is Iceland from 1955-2012.

Period
Total population at end of period
Live patients at end of period
Prevalence (per 100000$)$
SIR (per 100000 per year) $(95 \% \mathrm{Cl})$

\begin{tabular}{c}
$1955-1972$ \\
\hline 210.912 \\
14 \\
6.63 \\
$0.6(0.3-0.9)$ \\
\hline
\end{tabular}

\begin{tabular}{c}
\hline $1973-1982$ \\
\hline 235.538 \\
35 \\
14.86 \\
$1.3(0.8-1.8)$ \\
\hline
\end{tabular}

\begin{tabular}{c}
\hline $1983-1992$ \\
\hline 262.386 \\
70 \\
26.68 \\
$2.5(1.9-3.1)$ \\
\hline
\end{tabular}

\begin{tabular}{c}
\hline 1993-2002 \\
\hline 288.471 \\
208 \\
72.10 \\
$4.4(3.6-5.1)$ \\
\hline
\end{tabular}

\begin{tabular}{c}
\hline 2003-2012 \\
\hline 321.857 \\
372 \\
115.57 \\
$5.8(5.0-6.6)$ \\
\hline
\end{tabular}

www.eje-online.org 
negative imaging results were only included if they fulfilled all of the following criteria: hyperprolactinaemia, symptoms of hyperprolactinaemia, symptomatic and biochemical response to treatment with dopamine agonist. All other causes had been considered and eliminated (14 patients in total). Acromegaly or Cushing's disease was confirmed based on clinical presentation and biochemical evidence according to international guidelines and consensus statements $(12,13,14)$, along with consistent histopathological findings for those patients who underwent surgery. No thyroid-stimulating hormoneproducing adenomas have been diagnosed in Iceland. Adenomas measuring $10 \mathrm{~mm}$ or more in their greatest diameter were classified as macroadenoma, and adenomas $<10 \mathrm{~mm}$ as microadenoma. An adenoma was defined as being discovered incidentally if found during investigations for which pituitary disease could not have been an indication. For the purpose of longitudinal analysis, the total period was divided into five time periods allowing enough patients in each group to power statistical analysis (1955-1972, 1973-1982, 1983-1992, 1993-2002, 2003-2012). In this paper, the terms 'final prevalence' and 'final standardized incidence rate (SIR)' apply to calculated prevalence on the 31 December 2012 and SIR applying to the period 2003-2012 respectively.

\section{Statistical analysis}

The prevalence of PAs in general, and for each subtype, was calculated by dividing the number of patients with the total population at risk (population of Iceland) for each period and reported as cases/100 000 inhabitants.

Crude incidence rates were standardized against the World Health Organization 2000 standard population (15). The direct method was used and all reported incidence rates are standardized (SIR) and quoted as cases/100 000 per year. Using the Wilson's method, 95\% CIs were calculated. Associations between categorical variables were analysed using contingency tables and applying the $\chi^{2}$ and Fisher's exact test. A two-sided $P<0.05$ was considered significant. Statistical analysis and the generation of graphics was performed using the ' $\mathrm{R}$ ' statistical language and environment (16).

\section{Results}

\section{Prevalence}

At the end of the study period (31 December 2012) the total population of Iceland was 321857 inhabitants.
Given that 372 patients were alive, the final prevalence for PAs was $115.57 / 100000$. The final prevalence for women was 72.08/100 000 and men 43.49/100 000 . Prolactinomas had the highest prevalence of 54.37/ 100000 followed by NFPAs (41.32/100 000), acromegaly $(13.67 / 100000)$, and Cushing's disease $(6.21 / 100000)$ (Table 2).

More detailed data on each subtype and prevalence data can be found in Tables 1 and 2 and in Fig. 1 .

As shown in Table 1 the overall prevalence rate has risen from $6.63 / 100000$ in 1972 to $115.57 / 100000$ in 2012 , mainly explained by a steep rise in diagnosis since around 1990 (Fig. 2).

\section{All tumours diagnosed during 1955-2012}

A total of 471 patients were identified during the period of 1955-2012 in the whole of Iceland: 190 were men (40.3\%) and 281 women (59.7\%). NFPAs were the most commonly diagnosed adenomas (43.1\%), followed by prolactinomas (39.9\%), and acromegaly (11.3\%). Cushing's disease was the least common (5.7\%). NFPA was therefore the most common diagnosis over the whole period, but prolactinomas had the highest final prevalence rate (Supplementary Fig. 1A, see section on supplementary data and and Supplementary Fig. 2 given at the end of this article).

More women had prolactinomas than men $(\mathrm{M} / \mathrm{F}$ : 47/141; $P<0.001)$. Insignificantly more men presented with a NFPA than women (M/F: 104/99; NS). More men presented with acromegaly, but the difference did not reach statistical significance (M/F: 32/21; NS). Significantly more women were diagnosed with Cushing's disease $(\mathrm{M} / \mathrm{F}: 7 / 20 ; P<0.05)$ (Supplementary Fig. $1 \mathrm{C}$, see section on supplementary data given at the end of this article and Table 2).

Macroadenomas were more common than microadenomas $(54.8 \%$ vs $41.2 \% ; P<0.05)$. Macroadenomas present at a significantly higher age (median age, 54) than microadenomas (median age, 36$)(P<0.001) ; 60.1 \%$ of all macroadenomas were NFPAs.

The majority of men presented with a macroadenoma (73.2\% vs $43.2 \%$ for women $P<0.001$ ), but the majority of women presented with a microadenoma $(55.2 \%$ vs $20.5 \%$ for men $P<0.001$ ) (Table 2). Due to old imaging techniques or imprecise autopsy results, 19 cases (4\%) had an unknown adenoma size.

The median age at diagnosis for the whole cohort was 44 years (range: 4-94). Men presented at a significantly higher age than women (median age: 54 vs $37 ; P<0.001$ ). Patients with a macroadenoma also presented at a 
Table 2 Data on all pituitary adenomas diagnosed in Iceland from 1955 to 2012 and final data on prevalence.

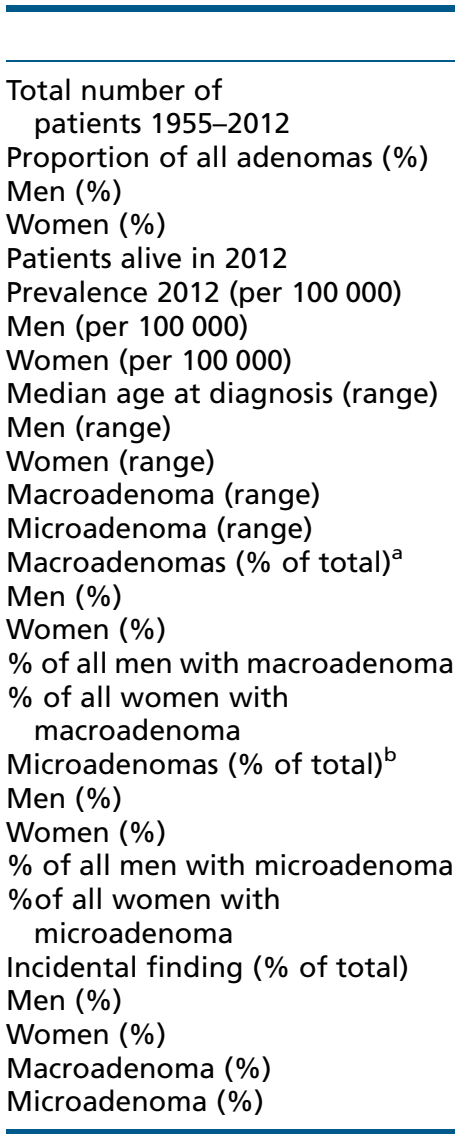

\begin{tabular}{|c|c|}
\hline All adenomas & NFPA \\
\hline 471 & 203 \\
\hline 100 & 43.1 \\
\hline $190(40.3 \%)$ & $104(51.2 \%)$ \\
\hline $281(59.7 \%)$ & $99(48.8 \%)$ \\
\hline 372 & 133 \\
\hline 115.57 & 41.32 \\
\hline 43.49 & 20.50 \\
\hline 72.08 & 20.81 \\
\hline 44 years (4-94) & 57 years (13-88) \\
\hline 54 years $(15-86)$ & 61 years (17-86) \\
\hline 37years (4-94) & 53 years $(13-88)$ \\
\hline 54 years (4-88) & 61 years $(14-88)$ \\
\hline 36 years (12-94) & 44 years (13-84) \\
\hline $258(54.8 \%)$ & $151(74.4 \%)$ \\
\hline $139(53.9 \%)$ & $89(58.9 \%)$ \\
\hline $119(46.1 \%)$ & $62(41.1 \%)$ \\
\hline $73.2 \%$ & $85.6 \%$ \\
\hline $42.3 \%$ & $62.6 \%$ \\
\hline $194(41.2 \%)$ & $45(22.2 \%)$ \\
\hline $39(20.1 \%)$ & $11(24.4 \%)$ \\
\hline 155 (79.9\%) & $34(75.6 \%)$ \\
\hline $20.5 \%$ & $10.6 \%$ \\
\hline $55.2 \%$ & $34.3 \%$ \\
\hline $76(16.1 \%)$ & $62(30.5 \%)$ \\
\hline $35(46.1 \%)$ & $27(43.5 \%)$ \\
\hline $41(53.9 \%)$ & 35 (56.6\%) \\
\hline $46(60.5 \%)$ & $36(58.0 \%)$ \\
\hline $25(32.9 \%)$ & $22(35.5 \%)$ \\
\hline
\end{tabular}

\begin{tabular}{c}
\hline Prolactinoma \\
\hline 188 \\
39.9 \\
$47(25.5 \%)$ \\
$141(75.0 \%)$ \\
175 \\
54.37 \\
13.04 \\
41.32
\end{tabular}

$\frac{\text { Acromegaly }}{53}$

Cushing's

35 years (13-94)

47 years $(24-73)$

32 years $(13-94)$

42 years $(15-85)$

32.5 years $(13-94)$

$68(36.2 \%)$

$30(44.1 \%)$

$38(55.9 \%)$

$63.8 \%$

$26.7 \%$

11.3
$32(60.4 \%)$
$21(39.6 \%)$
44
13.67
9.01

27

27

5.7

$7(25.9 \%)$

$20(74.1 \%)$

20

6.21

0.93

5.28

45 years $(4-83) \quad 42$ years $(12-76)$

45 years (15-83) 47 years $(26-74)$

44 years $(4-75) \quad 40$ years $(12-76)$

39 years (4-73) 51.5 years $(33-76)$

48.5 years $(39-83) \quad 41$ years $(12-75)$

$\begin{array}{rr}35(66.0 \%) & 41 \text { years }(12-75) \\ 20(57.1 \%) & 4(14.8 \%)\end{array}$

$20(57.1 \%) \quad 0(0 \%)$

$15(42.9 \%) \quad 4(100 \%)$

$62.5 \%$
$71.4 \%$

$0 \%$

$118(62.8 \%)$
$16(13.6 \%)$
$102(86.4 \%)$
$34.0 \%$
$72.3 \%$
$12(6.4 \%)$
$6(50.0 \%)$
$6(50.0 \%)$
$9(75.0 \%)$
$3(25.0 \%)$

$14(26.4 \%)$
$9(64.3 \%)$
$5(35.7 \%)$
$28.1 \%$
$23.8 \%$

$1(1.9 \%)$
$1(100 \%)$
$0(0 \%)$
$1(100 \%)$
$0(0 \%)$

$20 \%$

alt was not possible to confirm adenoma size in 19 cases. The sum of macro-and microadenomas is therefore not $100 \%$.

${ }^{\mathrm{b}}$ Patients with negative imaging results were classified as having a microadenoma.

significantly higher age than those with a microadenoma (median age: 54 vs $36 ; P<0.001$ ). The median age at diagnosis has not changed significantly since the beginning of the study period (Table 2, Supplementary Fig. 2, see section on supplementary data given at the end of this article).

A minority of all adenomas were discovered incidentally $(16.1 \%)$. There was no significant difference in numbers or prevalence of incidentally discovered adenomas between the sexes. Most were macroadenomas (60.5\% vs $32.0 \%$ microadenomas; $P<0.05)$. The majority $(81.2 \%)$ were NFPAs and they represent $30.5 \%$ of all NFPAs diagnosed: $15.8 \%$ were prolactinomas, $1.3 \%$ were acromegaly, and $1.3 \%$ Cushing's disease.

\section{Incidence}

The overall SIR rose significantly throughout the study period, from $0.6 / 100000$ per year for the period of 1955-1972 to 5.8/100 000 for the period of 2003-2012
(Table 1, Fig. 3). Since 1983 women have had a significantly higher overall SIR than men. For men, NFPAs have always had the highest SIR, but prolactinomas have shown the highest SIR among women since 1973 (Supplementary Table 1, see section on supplementary data given at the end of this article, Fig. 3). Macroadenomas have always had a higher SIR than microadenomas among men, but since 1983 microadenomas predominate in women (Supplementary Table 2 given at the end of this article). The SIR for incidentally discovered adenomas rose throughout the period, but significantly less than for symptomatic adenomas. Their incidence and prevalence increase with age (Supplementary Table 2 given at the end of this article, Supplementary Figs 4 and 5 given at the end of this article). As evident in the data presented in Table 2 women present at a younger age than men. The SIR for women reaches its peak at the age of 35-39 years, but at 70-74 years for men (Supplementary Table 1 and Supplementary Fig. 6 given at the end of this article given at the end of this article). 


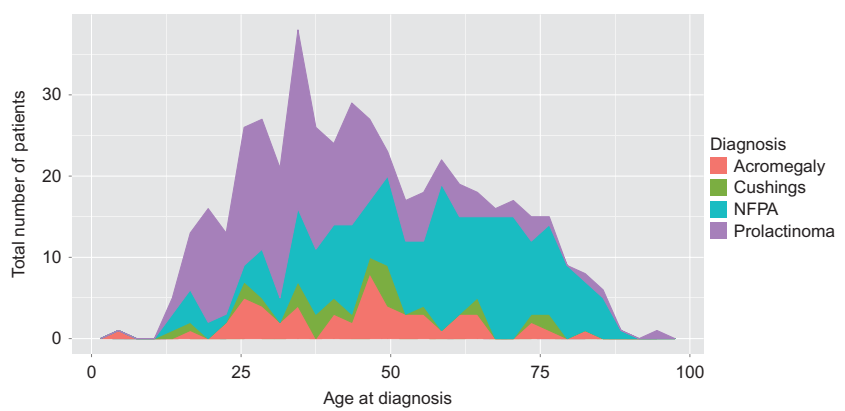

Figure 1

Age at diagnosis. Age at diagnosis for all four tumour subtypes. Non-functioning pituitary adenomas (NFPAs) are diagnosed at a significantly higher age than prolactinomas $(P<0.001)$.

\section{Non-functioning pituitary adenoma}

NFPAs were most frequently diagnosed over the whole period $(43.1 \%)$ but had the second highest final prevalence rate $(41.32 / 100000)$ and SIR $(2.2 / 100000$ per year for women vs 2.6/100 000 per year for men) after prolactinomas. There was an insignificant total male predominance ( $51.2 \%$ vs $48.8 \%)$. For the final time period the SIR for men was higher than for women but the difference did not reach statistical significance. Men presented at a significantly higher age than women (median age: 61 vs 53 for women; $P<0.05$ ) and more had a macroadenoma ( $85.6 \%$ vs $62.6 \% ; P<0.05)$.

\section{Prolactinoma}

Prolactinomas were the second most commonly diagnosed subtype (39.9\%) throughout the study period. Their final prevalence was the highest $(54.37 / 100000)$ as was their final SIR for women (3.6/100 000 per year), which is significantly higher than that for men $(1.4 / 100000$ per year $)(P<0.05)$. Prolactinomas have had the highest SIR among women out of all subtypes since 1973 (Supplementary Table 1, see section on supplementary data given at the end of this article). The median age at diagnosis was 35 years and was significantly lower for women (median age: 32 vs 47 for males; $P<0.001)$. The majority of women had a microadenoma $(72.3 \%)$ compared with $34 \%$ of men $(P<0.001)$.

\section{Acromegaly}

Acromegaly was the third most common diagnosis (11.3\%). Final prevalence was $13.67 / 100000$ and SIR $0.8 / 100000$ per year for men and $0.4 / 100000$ per year for women. There was a male predominance with a statistically significant difference in final SIR $(P<0.05)$ and final prevalence rates $(9.01 / 100000$ for men vs $4.66 / 100000$ for women; $P<0.05$ ). The median age at diagnosis was 45 years and did not differ significantly between the sexes. A significant majority among both sexes presented with a macroadenoma $(62.5 \%$ for men and $71.4 \%$ for women).

\section{Cushing's disease}

Cushing's disease was the least common diagnosis, representing only $5.7 \%$ of the total number. Final prevalence reached $6.21 / 100000$, with a significant female predominance $(5.28 / 100000$ vs $0.93 / 100000$ for men; $P<0.05)$. The SIR for men remained low throughout the period, peaking at 0.3/100 000/year between 1983 and 1992 but rose to $0.5 / 100000 /$ year for women within the final period. The majority of women had a microadenoma (70\%), but because of limited information about size and characteristics on male patients diagnosed before 1990, further statistical analysis is impossible. The median age at diagnosis was 42 , with no significant difference between the sexes.

\section{Discussion}

This is the first nationwide population-based study to establish the prevalence and incidence of PAs in a welldefined population over an extended period of time. Knowledge of the exact prevalence and current incidence of PAs is important to realise their true disease burden and

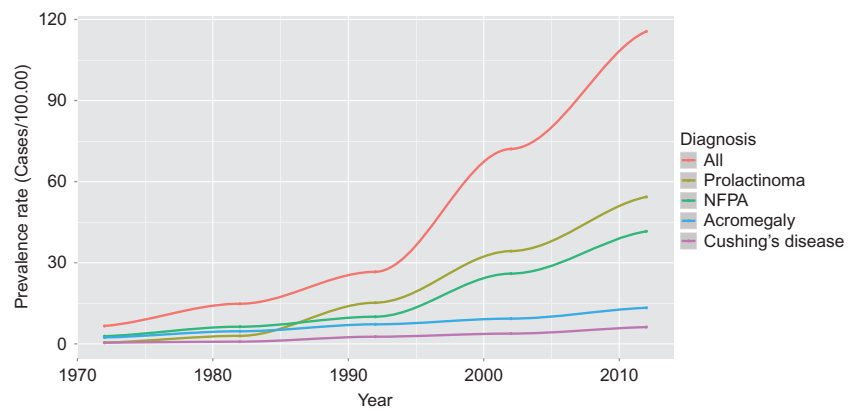

Figure 2

Changes in prevalence over time. Changes in prevalence rates for clinically significant pituitary tumours during 1972-2012 showing a clear rise since around 1990, mainly explained by the rising prevalence of prolactinomas and NFPAs. 
(a)

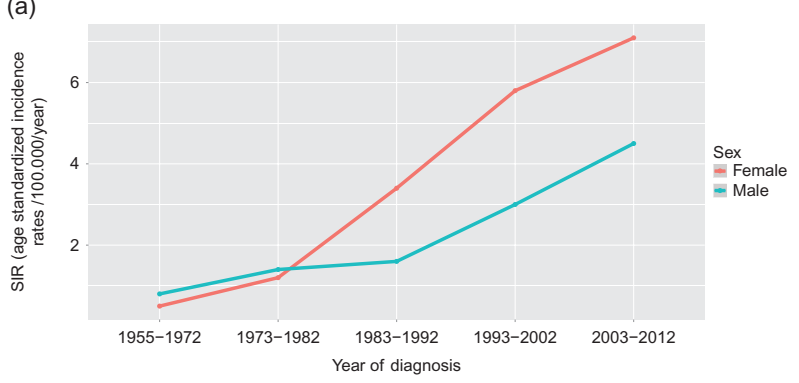

(b)
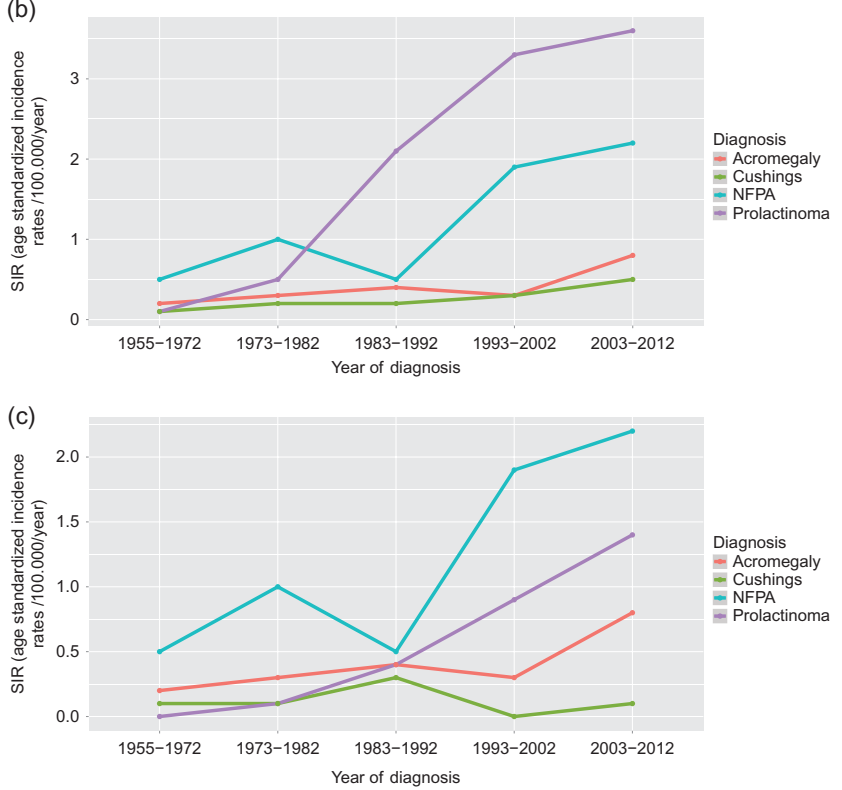

\section{Figure 3}

Standardized incidence rates (SIR) for pituitary adenomas in Iceland during 1955-2012. (A) Total SIR for men and women.

(B) SIR for each pituitary adenoma subtype during 1955-2012 for women. (C) SIR for each pituitary adenoma subtype during 1955-2012 for men. NFPA=non-functioning pituitary adenoma.

associated costs. This has long been a matter of significant debate, and studies through time have shown somewhat discordant results. Over 90 years ago, Costello conducted the first dedicated epidemiological study and found a prevalence of PAs of $22.5 \%$ at autopsy on asymptomatic subjects (17). A more recent systematic review of seven autopsy series found an overall prevalence of $14.4 \%$ (18). With the development and increased availability of pituitary imaging modalities, identification of PAs has become easier. The exact implication of this development is challenging to ascertain, but a review of available studies found a mean prevalence of $22.3 \%$. In this same review by Ezzat et al. (18) a combined analysis including both radiological and autopsy data yielded a final prevalence of unsuspected PAs of $16.7 \%$.

Data from large databases such as cancer registries both in Europe and the USA suggest that PAs constitute $5-20 \%$ of primary central nervous system tumours and are the most common type both by site and by histology in young adults (20-34 years of age) $(19,20,21)$.

These studies therefore suggest that PAs are common in the general population but most of them have no obvious clinical impact. Few well-designed intensive epidemiological studies on clinically significant PAs have been conducted. Studies done in the 1990s in the UK and Italy showed a prevalence of less than 300/million $(22,23)$. These retrospective studies done at tertiary referral centres are difficult to interpret because of the inability to define precise catchment areas and referral practices, and they do not represent a geographically defined population. In 2006 Daly et al. (6) conducted a cross-sectional study of PAs within the Liége province of Belgium, including a population of 71972 . They found a mean prevalence of 94 cases per 100 000. Prolactinomas were most frequent (66.2\%); $14.7 \%$ of patients had NFPAs, $13.2 \%$ had acromegaly, and 5.9\% had Cushing's disease (6). A more recent cross-sectional community-based study in Oxfordshire in the UK showed a similar prevalence of 77.6/100 000 inhabitants (7). A population-based study in Malta found an overall prevalence rate of 75.7/100 000 inhabitants in 2011, and an SIR of 4.27/100 000/year (8) based on a population of around 400000 inhabitants and estimating SIR between 2000 and 2011. A previous Finnish study had found an overall SIR of 4.0/100 000 per year (10).

Our total prevalence rate of 115.57/100 000 is higher than that of any previous study. It is similar, but higher, than that reported by Daly et al. (94/100 000) (6), and even higher than that reported by Fernandez et al. (77.6/100 000) (7) and Gruppetta et al. (75.7/100 000) (8). Our final SIR of 5.8/100 000 per year is also higher than that previously reported in Malta (4.27/100 000 per year) (8) and by Raappana et al. (10) in Finland (3.98/100 000 per year). Possible reasons for these higher rates might include easier access to diagnostic facilities and medical staff in Iceland with more frequent imaging and earlier diagnosis, or possibly a trend related to these specific populations, such as genetics or environmental factors.

Our study does confirm the overall trends noted in the most recent studies, with rising prevalence rates and SIRs along with an increasing predominance of NFPAs. It is interesting to note that the prevalence in Iceland is now nearing half that of other much more recognized conditions, such as type 1 diabetes mellitus. 
Our rank of subtype prevalence is the same as in all previous population-based studies - prolactinomas $>$ NFPA $>$ acromegaly $>$ Cushing's disease - although their exact prevalence and incidence varies somewhat from previous studies. We found $47 \%$ of adenomas to be prolactinomas in 2012. This is very similar to that reported by Gruppetta et al. (46.2\%) (8) but lower than that found by Daly et al. (66\%) (6) and Fernandez et al. (57\%) (7). We found 36\% to be NFPA, which again is almost identical to that described in Malta, but higher than that in Belgium and the $\operatorname{UK}(6,7,8)$. The main trend observed is increased prevalence and incidence of NFPAs, with relative reduction in other subtypes compared with older studies. This may partly be related to the increased use of imaging facilities with an improved resolution and increased number of incidentalomas of which the majority are NFPAs. This, however, does not explain this trend fully (Supplementary Fig. 4, see section on supplementary data given at the end of this article). This may also be related to more accurate diagnoses, including that of NFPA with modest hyperprolactinaemia related to other causes possibly previously diagnosed as a prolactinoma. NFPAs are the most frequently diagnosed adenomas overall, but prolactinomas are the most prevalent at the end of the period. This may be related to the younger age at diagnosis for prolactinomas and possibly the high age at diagnosis and related mortality for patients diagnosed with NFPA. Although the current prevalence data may be the most obvious measure of disease burden, we believe the total number of tumours diagnosed reflects different but important aspects of disease burden. It is therefore important to present both types of data for comparison. Patients with prolactinomas are, for example, younger at diagnosis, resulting in higher cumulative prevalence, often requiring relatively simple treatment with dopamine agonists for a defined period of time. Patients with NFPAs are older, have more co-morbidities, and more often require surgery and more complex follow-up requiring more resources.

Our prevalence rate for acromegaly of $13.67 / 100000$ is similar to that reported by Gruppetta et al. (12.45/100 000) (8) but higher than that reported in the UK and Belgium $(6,7)$. The SIR reported in Iceland for the period of 2003-2012 (0.8/100 000 per year for men and 0.4/100 000 per year for women) is higher than that reported in both Malta and Finland $(8,10)$.

We found the prevalence of Cushing's disease to be higher than that found by Fernandez et al. and Gruppetta et al. $(6.21 / 100000$ vs $1.2 / 100000$ and 2.2/100 000 respectively) $(7,8)$ but more similar to that reported by Daly et al. (6). Cushing's disease is a very rare condition and much larger sample sizes are needed to fully assess the significance of these differences. We found a strong female predominance, which is similar to previous populationbased studies.

In our study, the majority of adenomas were macroadenomas, and their final prevalence was higher than all other recent population-based studies but may again be related to the increasing prevalence of NFPAs and the increasing age of the general population, NFPA having a higher median age at diagnosis than other adenomas.

As noted in all previous studies, women present at a younger age with a higher proportion of microadenomas. In our study, the peak SIR for women is between the ages of 30 and 39 years, which corresponds well with previous studies reporting SIR. This tendency is probably related to the earlier presentation of women of childbearing age with hyperprolactinaemia due to menstrual irregularities and infertility than men with the corresponding symptoms of loss of libido, impotence, and general fatigue. This may of course be explained by a higher incidence of prolactinomas in this cohort, but it is important to note that NFPAs with modest prolactin rise can present with similar symptoms $(24,25)$. The peak SIR for the whole cohort is for men between the ages of 70 and 74 years (Supplementary Fig. 6, see section on supplementary data given at the end of this article), which differs from previous studies $(8,10)$, but may again relate to the increased incidence of NFPAs and advancing age of the population.

As previously described, this study includes 14 patients with negative imaging who fulfilled other diagnostic criteria for prolactinomas. This does differ from some previous studies. Excluding these patients, the total final prevalence for PAs falls to 111.22/100 000 and 50.02/100 000 for prolactinomas specifically. The study also includes four patients with Cushing's disease and three patients with acromegaly with negative imaging, who also fulfilled clinical and biochemical criteria and responded to treatment.

The median age at diagnosis in our study was 44 years, which is higher than in any other recent study. Gruppetta et al. found a median age of 39 years (8), Daly et al. 40.3 years (6), Fernandez et al. 37 years (7), and Raappana et al. 40 years (10). The age distribution is similar, however, with men and NFPAs presenting at an older age. Although the age range is wide (4-94 years), this does represent a relatively young economically productive population, which does stress the importance of the appropriate use of resources in their management.

A recent study using incidence data from 49 population-based state cancer registries in 2004-2009 in the 
USA showed a significant rise in SIR during this period, as well as a significantly higher SIR in blacks (26). Iceland has a homogenous, well-defined population almost exclusively of white descent. This may be important when comparing our findings to other populations.

This study includes every PA diagnosed or registered in the total population of Iceland during the study period using all available diagnostic modalities. This approach differs somewhat from previous studies. Between the years 1958 and 1993, seven cases were registered in the Icelandic Cancer Register as having been found at autopsy (Supplementary Table 3 , see section on supplementary data given at the end of this article). These are not included in the prevalence data but are included in the total number of cases. Their inclusion does not significantly affect SIRs calculated for any adenoma types since 1973. All seven adenomas are classified as NFPAs. Despite their exclusion, NFPAs remain the most commonly diagnosed adenomas in total $(41.6 \%)$.

The rising incidence and prevalence of PAs have often been thought to be related to the increased use of imaging and increased incidence of incidentally discovered adenomas of uncertain significance. In our study, the vast majority of patients were symptomatic with only $16.1 \%$ of all adenomas being true incidental findings. Of these, seven were discovered at autopsy, so only 69 adenomas were diagnosed incidentally on imaging since 1955 . The final prevalence of incidentally discovered adenomas was $15.89 / 100000$, slightly higher than that of acromegaly. It must be kept in mind that symptoms related to pituitary dysfunction can be very diffuse and non-specific, and they should therefore be included in the differential diagnosis of a variety of symptoms. The incidence data supports this by showing a modest rise in SIR for incidentalomas over the last 20 years but not nearly steep enough to explain the overall rise in SIR and prevalence rates (Supplementary Fig. 4, see section on supplementary data given at the end of this article).

The increasing availability of imaging modalities in Iceland is well documented. Prior to the introduction of the first CT scanners in 1981, imaging was done with standard X-ray. The first 0.5T MRI scanner arrived in 1992 followed by a 1.0T scanner in 1994 and a $1.5 \mathrm{~T}$ scanner in 2004. Although it is impossible to be certain of a causal relationship, this corresponds well to the initial rise in frequency, especially for prolactinomas and NFPAs following the introduction of MRI (Supplementary Fig. 3 , see section on supplementary data given at the end of this article). As most are symptomatic, this probably relates to a more accurate diagnosis using the appropriate investigational tools rather than simple chance findings because of more frequent high definition imaging.

The limitations of this study include it being a retrospective observational exercise. Despite this, we are confident the cohort identified in this intensive case finding procedure is complete, as access was gained to all investigational and treatment facilities in Iceland. Unlike other recently published studies, we have included all incidentally discovered adenomas, which may explain the rising predominance of NFPAs. Incidentally discovered adenomas do require follow-up, treatment, and resources. In our cohort there was no significant difference in the proportion of patients needing surgery depending on presentation (symptomatic $30.2 \%$ vs incidental $27.6 \%$ ). Characteristics of both groups are presented in Table 2 . There is a possibility that patients with modest hyperprolactinaemia followed up by general practitioners or other specialist may have been missed, but these would not have had any imaging or any contacts at secondary or tertiary care. Their inclusion in the study would therefore, in any case, have been debatable.

The accurate clinical diagnosis and subclassification of PAs can be challenging. All clinical information and investigative results for all cases were scrutinised by a consultant endocrinologists using objective measures and internationally recognised guidelines and consensus statements where possible. Most patients had been followed and had contact with a number of specialists over an extended period of time, confirming their diagnosis. The data available on patients diagnosed prior to modern research facilities and the implementation of guidelines and consensus statements is in many ways limited, and diagnoses are not as firm. All available data was examined and upmost care taken to review every diagnosis using modern approaches. This applies to a small minority of our total cohort, and we believe we have made the most of the data available.

\section{Conclusion}

In this nationwide epidemiological study on PAs spanning almost six decades, we have confirmed their rising prevalence rates and standardized incidence rates. Compared with other recent studies, we did, however, find higher overall prevalence rates and incidences rates, which are not explained by incidental findings. There is a chronological relationship with the introduction of imaging modalities, but the vast majority of patients are symptomatic having appropriate investigations for their symptoms. Higher prevalence and incidence rates 
underline the importance of increased awareness and education of all health care providers along with the appropriate allocation of resources.

\section{Supplementary data}

This is linked to the online version of the paper at http://dx.doi.org/10.1530/ EJE-15-0189.

\section{Declaration of Interest}

The authors declare that there is no conflict of interest that could be perceived as prejudicing the impartiality of the research reported.

Funding

The authors received no external funding for this project.

\section{Author contribution statement}

All authors contributed sufficiently in the work to take public responsibility for its content. T T Agustsson, J G Jonasson, V Steinthorsdottir, G Sigurdsson, A V Thorsson, P V Carroll, M Korbonits, and R Benediktsson were involved in the study design. T T Agustsson and T Baldvinsdottir were involved in data collection. T T Agustsson, R Benediktsson, J G Jonasson, E Olafsdottir, P V Carroll, and M Korbonits were involved in data interpretation. T T Agustsson and E Olafsdottir were involved in statistical analysis. T T Agustsson drafted the manuscript. T T Agustsson, J G Jonasson, $\mathrm{R}$ Benediktsson, $\mathrm{P} \vee \mathrm{C}$ Carroll, and $\mathrm{M}$ Korbonits were involved in reviewing and improving the manuscript. Valgerður Steinpórsdóttir is affiliated with deCODE Genetics. Her contribution to this epidemiological study involves contribution to the study design and supervision through her role as a $\mathrm{PhD}$ supervisor in collaboration with the University of Iceland.

\section{Acknowledgements}

The authors would like to express our sincere gratitude to all clinicians who provided information and assisted in the data gathering, including Helga Agusta Sigurjonsdottir, Arna Gudmundsdottir, Gunnar Valtysson, Bolli Thorsson, and Ari J Johannesson. They would also like to thank all other members of the staff at Landspitali, Domus Medica, and the Hospital in Akureyri who contributed to the study.

\section{References}

1 Tomlinson JW, Holden N, Hills RK, Wheatley K, Clayton RN, Bates AS, Sheppard MC \& Stewart PM. Association between premature mortality and hypopituitarism. West Midlands Prospective Hypopituitary Study Group. Lancet 2001357 425-431. (doi:10.1016/S01406736(00)04006-X)

2 Van der Klaauw AA, Kars M, Biermasz NR, Roelfsema F, Dekkers OM, Corssmit EP, van Aken MO, Havekes B, Pereira AM, Pijl H et al. Disease-specific impairments in quality of life during long-term follow-up of patients with different pituitary adenomas. Clinical Endocrinology 200869 775-784. (doi:10.1111/j.1365-2265. 2008.03288.x)

3 Dekkers OM, van der Klaauw AA, Pereira AM, Biermasz NR, Honkoop PJ, Roelfsema F, Smit JW \& Romijn JA. Quality of life is decreased after treatment for nonfunctioning pituitary macroadenoma. Journal of Clinical Endocrinology and Metabolism 200691 3364-3369. (doi:10.1210/ jc.2006-0003)

4 Matta MP, Couture E, Cazals L, Vezzosi D, Bennet A \& Caron P. Impaired quality of life of patients with acromegaly: control of GH/IGF-I excess improves psychological subscale appearance. European Journal of Endocrinology 2008158 305-310. (doi:10.1530/EJE07-0697)

5 Sughrue ME, Chang EF, Gabriel RA, Aghi MK \& Blevins LS. Excess mortality for patients with residual disease following resection of pituitary adenomas. Pituitary 201114 276-283. (doi:10.1007/ s11102-011-0308-1)

6 Daly AF, Rixhon M, Adam C, Dempegioti A, Tichomirowa MA \& Beckers A. High prevalence of pituitary adenomas: a cross-sectional study in the province of Liege, Belgium. Journal of Clinical Endocrinology and Metabolism 200691 4769-4775. (doi:10.1210/jc. 2006-1668)

7 Fernandez A, Karavitaki N \& Wass JAH. Prevalence of pituitary adenomas: a community-based, cross-sectional study in Banbury (Oxfordshire, UK). Clinical Endocrinology 201072 377-382. (doi:10.1111/j.1365-2265.2009.03667.x)

8 Gruppetta M, Mercieca C \& Vassallo J. Prevalence and incidence of pituitary adenomas: a population based study in Malta. Pituitary 2013 16 545-553. (doi:10.1007/s11102-012-0454-0)

9 Fontana E \& Gaillard R. Epidemiology of pituitary adenoma: results of the first Swiss study. Revue Médicale de Bruxelles 20095 2172-2174.

10 Raappana A, Koivukangas J, Ebeling T \& Pirilä T. Incidence of pituitary adenomas in Northern Finland in 1992-2007. Journal of Clinical Endocrinology and Metabolism 201095 4268-4275. (doi:10.1210/ jc.2010-0537)

11 Tulinius H. Multigenerational information: the example of the Icelandic Genealogy Database. Methods in Molecular Biology 2011675 221-229. (doi:10.1007/978-1-59745-423-0_11)

12 Nieman LK, Biller BMK, Findling JW, Newell-Price J, Savage MO, Stewart PM \& Montori VM. The diagnosis of Cushing's syndrome: an Endocrine Society Clinical Practice Guideline. Journal of Clinica Endocrinology and Metabolism 200893 1526-1540. (doi:10.1210/jc. 2008-0125)

13 Melmed S, Colao A, Barkan A, Molitch M, Grossman AB, Kleinberg D, Clemmons D, Chanson P, Laws E, Schlechte J et al. Guidelines for acromegaly management: an update. Journal of Clinical Endocrinology and Metabolism 200994 1509-1517. (doi:10.1210/jc.2008-2421)

14 Melmed S, Casanueva FF, Cavagnini F, Chanson P, Frohman L, Grossman A, Ho K, Kleinberg D, Lamberts S, Laws E et al. Acromegaly treatment consensus workshop participants. Guidelines for acromegaly management. Journal of Clinical Endocrinology and Metabolism 200287 4054-4058. (doi:10.1210/jc.2002-011841)

15 Ahmad, OB, Boschi-Pinto C, Lopez AD, Murray CJ, Lozano R, Inoue M. Age Standardization of Rates: a New Who Standard (Technical Report). GPE Discussion Paper Series: No. 31. Geneva, Switzerland: World Health Organization (WHO), 2001. (available at: http://www.who.int/ healthinfo/paper31.pdf).

16 R Core Team. R: A Language and Environment for Statistical Computing. R Foundation for Statistical Computing, Vienna, Austria, 2014. URL: http://www.R-project.org/.

17 Costello RT. Subclinical Adenoma of the Pituitary Gland. American Journal of Pathology 193612 205-2161.

18 Ezzat S, Asa SL, Couldwell WT, Barr CE, Dodge WE, Vance ML \& McCutcheon IE. The prevalence of pituitary adenomas: a systematic review. Cancer 2004101 613-619. (doi:10.1002/cncr.20412)

19 Ostrom QT, Gittleman H, Liao P, Rouse C, Chen Y, Dowling J, Wolinsky Y, Kruchko C \& Barnholtz-Sloan J. CBTRUS Statistical Report: Primary Brain and Central Nervous System Tumors Diagnosed in the United States in 2007-2011. Neuro-Oncology 201416 (suppl 4) iv1-iv63. (doi:10.1093/neuonc/nou223) 
20 Finnish Cancer Registry. Cancer in Finland 2005-2006. Helsinki, Finland: Cancer Society of Finland, 2009.

21 Nilsson B, Gustavasson-Kadaka E, Bengtsson BA \& Jonsson B. Pituitary adenomas in Sweden between 1958 and 1991: incidence, survival, and mortality. Journal of Clinical Endocrinology and Metabolism $2000 \mathbf{8 5}$ $1420-1425$.

22 Clayton RN. Sporadic pituitary tumours: from epidemiology to use of databases. Bailli?re's Best Practice \& Research. Clinical Endocrinology \& Metabolism 199913 451-460. (doi:10.1053/beem.1999.0036)

23 Faglia G. Epidemiology and pathogenesis of pituitary adenomas. Acta Endocrinologica 1993129 (Suppl 1) 1-5.
24 Franks S, Jacobs HS, Martin N \& Nabarro JD. Hyperprolactinaemia and impotence. Clinical Endocrinology 19788 277-287. (doi:10.1111/j.13652265.1978.tb02770.x)

25 Franks S \& Nabarro JD. Prevalence and presentation of hyperprolactinaemia in patients with 'functionless' pituitary tumours. Lancet $1977 \mathbf{1}$ 778-780. (doi:10.1016/S0140-6736(77)92959-2)

26 Gittleman H, Ostrom QT, Farah PD, Ondracek A, Chen Y, Wolinsky Y, Kruchko C, Singer J, Kshettry VR, Laws ER et al. Descriptive epidemiology of pituitary tumors in the United States, 2004-2009: Clinical article. Journal of Neurosurgery 2014121 527-535. (doi:10.3171/ 2014.5.JNS131819)

Received 17 February 2015

Revised version received 15 August 2015

Accepted 21 August 2015 